\title{
Trends in the profile of the Canadian physician pool
}

$\mathrm{T}$ he national physician pool is a bit older but fractionally larger than it was 5 years ago. It's also more likely that Canadians will be treated by a female physician, by someone who was educated outside of Canada or someone who has returned home to hang up a shingle after a stint abroad. It's more difficult to find a family physician in Nunavut than anywhere else in Canada.

Those are among the trends evident in the Canadian Institute for Health Information's most recent annual report on the supply, distribution and migration of physicians in Canada (2007).

The report indicates that the number of active (defined as someone with an MD degree and a valid mailing address) physicians grew by $7.1 \%$ between 2003 and 2007, to 63 682. An additional 7004 "excluded" physicians are either in the military, semiretired, completing residencies or are nonlicensed and requested exclusion from the tally. Including them raises the overall number of physicians in Canada to 70686.

Of the nearly 64000 "included" physicians, 32598 are practising family medicine, while 31084 are specialists.

The increased size of the workforce is a result of both an increase in the number of Canadians being trained as physicians (6.6\%), as well as an increase in the number of foreign-trained physicians licensed to practise $(4.5 \%)$.

The overall physician-to-population ratio in Canada increased to 192.1 per 100000 population in 2007 from 187 in 2003. The number of family practitioners per 100000 was 98 , while the number of specialists was 94.

Canadians in all regions have reported difficulties in finding family doctors, but the statistics indicate the problem is most pronounced in Nunavut, at 29, while there are more family physicians per 100000 in the Yukon, at 205, than anywhere else in Canada (Figure 1).

Overall, the Yukon Territory has the most physicians per 100000 population at 230, followed by Nova Scotia (228), Quebec (217), British Columbia (198), Alberta (197), Newfoundland and Labrador (192), New Brunswick (185), Manitoba (177), Ontario (176), Saskatchewan (163), Prince Edward Island (157), Northwest Territories (115) and Nunavut (29).

The statistics also indicate that Ontario continues to be the only jurisdiction in the country with more specialists per capita (91) than family practitioners (85). Nova Scotia leads the way in specialists per 100000 population at 113, followed by Quebec 106, Newfoundland and Labrador 99, Ontario 91, Alberta 90, British Columbia 90, New Brunswick 86, Manitoba 86, Saskatchewan 72, Prince Edward Island 58, Northwest Territories 31, the Yukon Territory 26 and Nunavut 3.

The overall physician pool also continues to grey. The average age of the physician workforce increased to 49.6 years in 2007 from 48.3 in 2003 . The average family physician was 48.9 years of age in 2007, while the average specialist was 50.5. The average age of male physicians was 51.9, while that of female physicians was 45.4 .

The number of female physicians increased by $15.2 \%$, while the number of male physicians increased by $2.9 \%$. In 2007, there were 21438 female physicians, or $33.8 \%$ of the workforce. The gender disparity is all but nonexistent among physicians under the age of 40 , as $49.4 \%$ are female and $50.6 \%$ male.

Saskatchewan has the highest percentage of foreign-trained medical graduates at $49 \%$, while Quebec and Nunavut have the lowest at $11 \%$. Most foreign-trained physicians come from the United Kingdom (2072), followed by South Africa (1971), India (1357), Ireland (1087), Egypt (623), the United States (493), France (439), Poland (412), Pakistan (286) and the Philippines (226).

The report also indicates that physicians are increasingly likely to retain their existing practices rather than pack their bags for another province. Similarly, the number of physicians returning to Canada from a stint abroad (142) continues to decline. That's the lowest rate in 5 years, as was the number of physicians leaving Canada (122). Only 550 physicians moved to another province or territory in 2007, again the lowest rate in 5 years. Those that moved most often went to British Columbia or Alberta. Wayne Kondro, CMAJ

DOI:10.1503/cmaj.081959

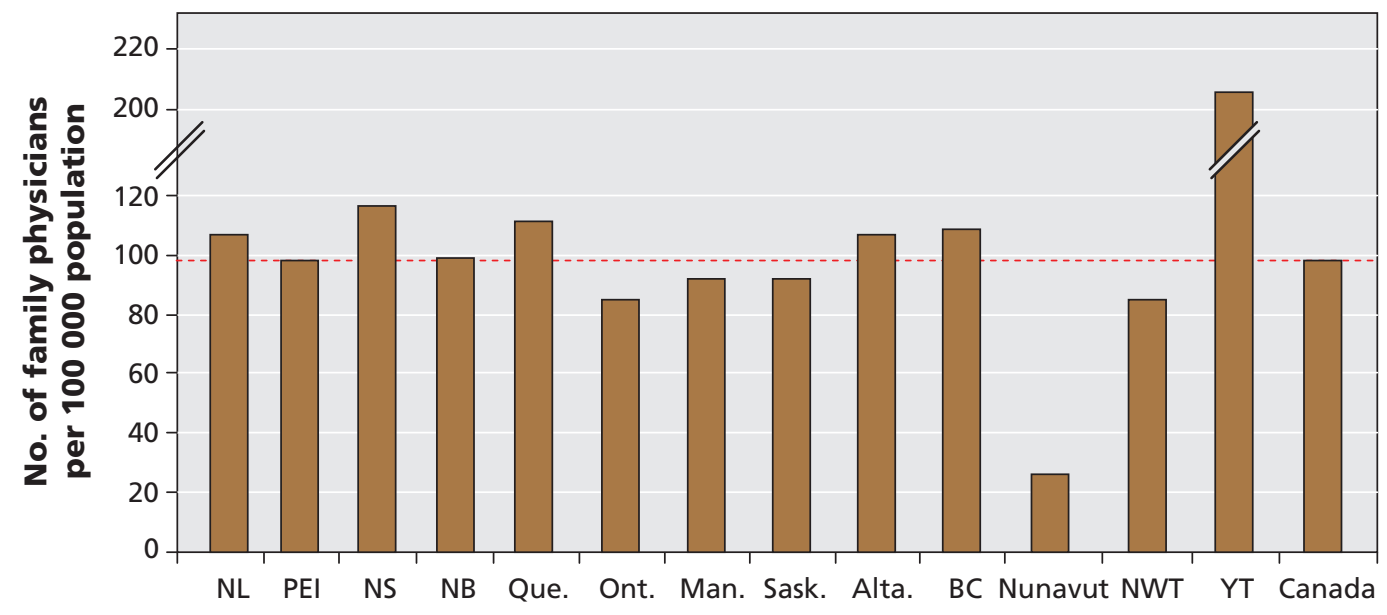

Figure 1: Provincial and territorial variations in the number of family physicians per capita. 